\title{
Substantiation model calculation diagram UES of Russia to take balance reliability
}

\author{
Mikhail Chukreyev ${ }^{1}$ \\ ${ }^{1}$ Federal Research Center "Komi Scientific Center of the Ural Branch Russian Academy of Sciences", ISE and EPN, 167000, Russia
}

\begin{abstract}
The principles formation the model design scheme UES of Russia are considered to justify the balance reliability in relation to modern conditions of infrastructure changes and intellectualization of energy systems. The definition of territorial zones equal reliability UES of Russia is based on topology information of electrical connections in the UES of Russia and a list of controlled sections in it. Studies on the possible aggregation the model design scheme for spectrum of source information available to researchers are presented.
\end{abstract}

\section{Introduction}

Ensuring balance reliability is associated with the determination and placement of a power reserve in the territorial zones (TK) of electric power system (EPS) and the Unified EPS (UES) of Russia in particular. This task has always been given due attention in planning development electric power industry for a short and long term. Some stagnation was observed in 90 s of the past and the beginning of this century. Since 2010, the attitude towards ensuring balance sheet reliability at the planning stage has changed. Since this year, on the instructions the Russian Ministry of Energy", JSC "UES of UES" together with PJSC "FGC UES" began annually carrying out the work "Scheme and Program for Development UES of Russia for a seven-year period".

The solution to the problem of providing the balance task is iterative. At each iteration, the problem of evaluating indicators of balance reliability (IBR) is solved, and depending on their difference from standard values, reserve funds change in territorial zones (TK) and levels of maximum permissible power flows (MPF). The process ends with the practical coincidence of the calculated for a particular backup option IBR with standard values. Thus, the main block in the justification the means to ensure balance sheet reliability is the block assessment of IBR.

The following factors and random events affect the values indicators of balance reliability in a complex EPS, and therefore the values standard power reserve:

- A model design scheme UES of Russia with allocated $\mathrm{TZ}$ and their connections;

- the available capacities of individual TZ and MPF stocks of links between them;

${ }^{a}$ Rules for development and approval schemes and programs for prospective development electric power industry, approved by Decree the Government of Russian Federation, October 17, 2009 No. 823 .
- structure generating capacities of TZ;

- scheduled equipment repairs;

- schedules changes in TZ loads by year and day;

- irregular load fluctuations and errors in forecasting consumer demand;

- decrease in the generating capacity of TZ and MPF reserves due to accidental damage to power plant units and power lines.

It is completely obvious that all of the factors listed above are taken into account when assessing IBR and are given in sufficient detail in monographs [1-3]. At the same time, the question of formation a model settlement scheme UES of Russia with the allocation the territorial zones and the links connecting them is still debatable and not completely worked out. Below, we consider the issues of creating a model design scheme for tasks of balance reliability, taking into account the modern realities of the functioning UES of Russia and existing power balances.

\section{Prerequisites for the justification model design scheme UES of Russia for the task of substantiating balance reliability}

In substantiating the balance sheet reliability of EPS development options at all times, a number of various assumptions were made that made it possible to simplify the solution of the problem. This is a representation of the power consumption mode, and a representation operation of generating equipment and much more [2]. The simplifications introduced in the long-term planning naturally relate to issues of aggregation electrical connections of the main generating and network facilities. It is clear that the introduced simplifications that have a certain impact on the decisions taken to manage the development of EPSs should have a certain justification. Therefore, the definition of territorial zones

\footnotetext{
* Corresponding author: chukreev@iespn.komisc.ru
} 
must comply with a number of requirements of a technical (technological) and economic nature.

The model design scheme UES of Russia should be presented in the form of a graph, the vertices which are zones equal reliability, and the edges are system-forming bonds. Zones equal reliability (hereinafter the territorial zone - a concentrated system ${ }^{b}$ ) are understood as a set of nodes included in the zone, network restrictions between which do not affect the IBR of the zone in question. Such a definition to some extent equates the concept of reliability zones and zones of free power flow (ZFPF).

In the current conditions introduction of market relations in the Russian electric power industry, the main goal of creating a model calculation scheme for the country's UES is to justify reservation tools for holding auctions for commercial power take-offs (CPT), power supply contracts (PSC) and other market procedures. CPT is focused on the selection of generating capacity in accordance with its demand from the power balances developed in the work of the S\&D UES. Demand for capacity in addition to the maximum load and export / import includes the value of the normative reserve capacity.

The use values of normative reserve of power, given in the methodological recommendations (MR) for the design and development energy systems when conducting CPT, [2], is currently not entirely correct. These MRs were developed by Institute Energosetproekt OJSC in the mid-90s of the last century, but were approved by the Ministry of Energy of Russia only in 2003. It should be noted that, at the stage of their development, retrospective information of the 80-90s of the last century was used, for which the situation was rather tense with the provision of generating capacity reserves territorial zones UES of the country. The task of substantiating the power reserves was solved in conjunction with the optimization MPF of the backbone links. At the same time, significant funds were required in the construction of new generating sources and system-forming links for the implementation of recommendations to achieve the required level of balance reliability or a minimum of reduced costs.

At present, it has become possible to obtain more detailed and reliable initial information for solving the problem of evaluating IBR and the means to ensure it [2], both by the modes of power consumption and probabilistically determined parameters about random outputs generating equipment for unscheduled repairs. The task of substantiating the power reserve today does not envisage the creation new generating sources and power lines (they are prescribed for the seven-year period in the work of the S\&D UES). In 2012, on instructions from JSC UES UES and JSC Institute Energosetproekt, new guidelines ${ }^{\mathrm{c}}$ were developed that partially took these factors into account, but they were not approved by the Russian Ministry of Energy. In

\footnotetext{
${ }^{\mathrm{b}}$ A power system is called a concentrated one, inside of which there are no restrictions on the transfer of power through power lines from one zone to another.

c Guidelines for designing development of energy systems / Institute Energosetproekt OJSC, 2012.
}

2018, the Russian Ministry of Energy initiated work on the creation of the "Procedure for determining the size regulatory reserve of generating capacities in the UES of Russia and isolated power systems" d.

The most difficult task in the formation of an acceptable model design scheme UES of Russia, in addition to highlighting the boundaries of $\mathrm{TZ}$, is the task of determining the MPF power links between them or MPF power in controlled sections. In this case, the model should not be excessively large. This follows from two important circumstances. The first is the difficulty of solving the problem of justifying the power reserve, consisting in the multiple solution problem of estimating the power supply circuit requiring playing a set of random system conditions caused by unplanned findings in the repair of generating and network equipment and load changes due to errors in its forecasting caused by the temperature factor. The second is to obtain the necessary range of source information that affects the for the selected territorial zones. Such information is provided only in the context of territorial zones in the form of integrated energy systems and partially regional ones in the work of the S\&D UES.

\section{Principles for determining territorial zones of equal reliability}

In modern conditions, they are based on the available information on the topology of electrical connections in the UES of Russia presented the work of the S\&D UES and the list of controlled sections between and within the UES. The latter information, unlike the map-scheme, is not given in open publications and can be provided, for example, by SO UES JSC. The validity of the use of MPF of controlled sections obtained during the operational management of operating conditions under operating conditions for the formation of technical specifications for tasks of balance reliability is not considered in this article. At the same time, certain assumptions about their use should be noted. They are calculated for a specific mode with a given composition and power of generating equipment, active and reactive load levels, weighting trajectories and many other parameters. In the process of assessing IBR, both the composition of the generating equipment and the levels of power consumption are randomly played. Therefore, for these states, the MPF stocks of controlled sections will not always correspond to reality.

The currently relevant controlled sections are independent of each other, since they were obtained by weighting the mode for different electrical modes of the updated design scheme UES of Russia. This suggests that the application of any laws of transformation of the regime parameters in the problem of circuit equivalentization and obtaining power flows from individual section connections based on data on flows obtained for another section is fundamentally impossible.

\footnotetext{
d The task of NP Market Council JSC to perform work of the same name.
} 
Given the independence of the controlled sections, the algorithm for allocating $\mathrm{TZ}$ of equal reliability is quite simple. It consists in combining in one $\mathrm{TZ}$ those nodes that do not have any specified restrictions on power transmission. Thus, many $\mathrm{TZ}$ is obtained that can be used in the formation model design scheme. In fig. 1, for some fragment of the EPS, three $\mathrm{TZ}$ and two bonds between them (I and II) are distinguished. It can be seen that inside the allocated TZ, there are no restrictions on the transmission of electricity between the nodes entering it.

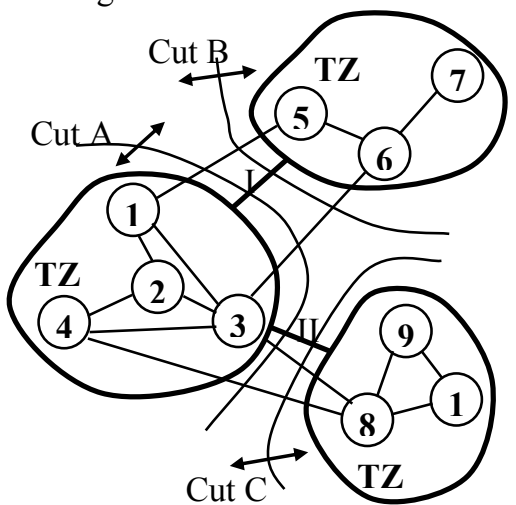

Fig. 1 Fragment EPS scheme

The most difficult is the question of determining the power MPF for the formed and physically nonexistent connections I and II between the selected TZ. There are conflicting questions about the choice of the power MPF values in the forward and reverse directions (a doubleheaded arrow in Fig. 1) for bonds I and II - from the MPF values of sections $\mathrm{A}$ and $\mathrm{B}$ and sections $\mathrm{A}$ and $\mathrm{C}$, respectively. At the same time, it is impossible to simplify based on the laws of electrical engineering, due to the independence of the cross sections. The simplest method, which does not lead to any additional errors, is to take into account, at each random state, the restrictions on power transfer not by links (I and II), but directly by controlled sections $\mathrm{A}, \mathrm{B}$ and $\mathrm{C}$ (see the next section).

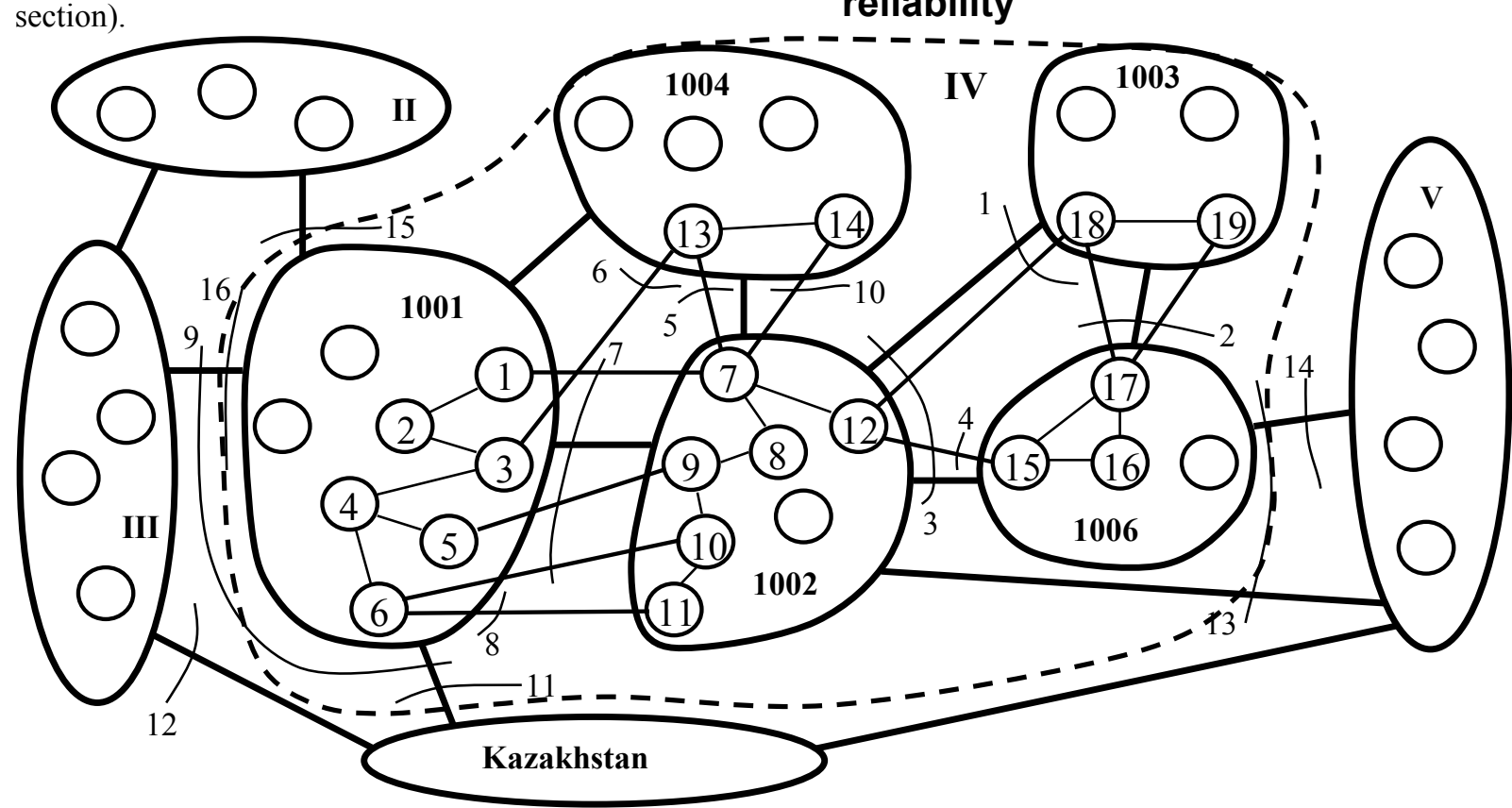

Fig. 2 Ural scheme and its relationship with neighboring UES.

II - Center; III - Middle Volga; IV - Urals; V - Siberia; 1001-1006 - The zones of reliability Urals UES allocated by SO UES.

After completion the process of formation design scheme, it is necessary to reduce the number of territorial zones to a certain minimum (in foreign and domestic practice to 100). This can be achieved by considering the impact of one controlled section on another from the standpoint of ensuring balance reliability. Such an approach requires detailing the source information for all the territorial zones identified at the first stage.

For example, consider the Ural. If we consider all 190 controlled sections in this UES, then according to the above algorithm, $62 \mathrm{TZ}$ and more than 100 connections between them (most often physically nonexistent) can be formed. Specialists of SO UES, JSC, by combining reliability zones, both on a territorial basis and taking into account their interconnectedness, allowed reducing the number of $\mathrm{TZ}$ to five (Fig. 2). These $\mathrm{TZ}$ have a pronounced territorial division and are interconnected by powerful lines with a voltage of 500 $\mathrm{kV}$. The equivalent bonds formed in this case are determined by 1-3 real lines (in Fig. 2, the links between zones 1001-1004, 1002-1003, 1004-1002, 1002-1006 and 1006-1003) and in only one case more than 3 (Fig. 2 links between zones 1001-1002). Considering this scheme (Fig. 2) from the standpoint of using controlled sections, it can be seen that any of the equivalent bonds is well replaced by a set of sections defining it. Moreover, inside the allocated $\mathrm{TZ}$, there are no restrictions on the transmission of electricity between the nodes entering it. Similarly, relationships with other UESs are described.

\section{The ability to account for controlled sections in the model of the design scheme for the task of ensuring balance reliability}




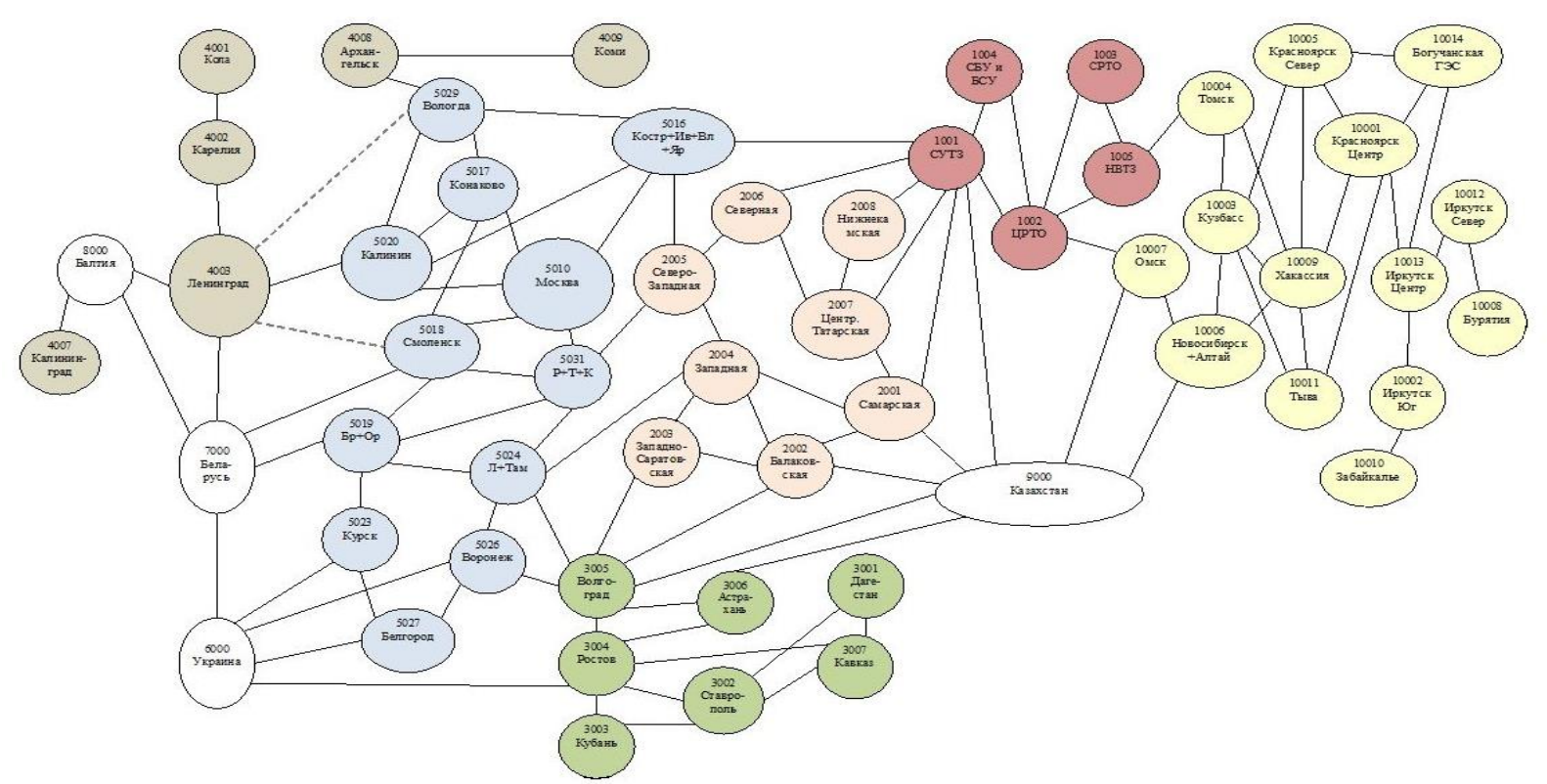

Fig. 3. The model calculation scheme balance sheet reliability UES of Russia without the East.

1001 - 1: 1002 - 2; 1003 - 3; 1004 - 4; 1005 - 5- Ural; 2001 - 6: 2002 - 7; 2003 - 8; 2004 - 9; 2005 - 10: 2006 $11 ; 2007-12 ; 2008$ - 13 - Middle Volga;

$3001-14: 3002-15 ; 3003-16 ; 3004-17 ; 3005-18: 3006-19 ; 3007-20$ - South; $4001-21: 4002-22 ; 4003-23 ; 4007-24 ; 4008-25 ; 4009$ - 26- North-West;

Under the conditions when there is information only on the restrictions of power flow over individual sections of the model of the design scheme of the EPS (Fig. 1), the most acceptable way to solve the problem of assessing a randomly generated state of the system by generating power and load is to take into account precisely these restrictions. With this in mind, the following is a correction of the random state estimation model (power deficit distribution unit) in the EPS, for the case of using the maximum allowable flows in controlled sections as restrictions on power flows between territorial zones. It is clear that the objective function (1) and restrictions (2) - (5) should remain unchanged:

$$
\sum_{j=1}^{n} c_{j}^{H}\left(\bar{P}_{j}^{H}-P_{j}^{H}\right) \rightarrow \min ,
$$

with constraints:

$$
\begin{array}{cc}
P_{j}^{H}-P_{j}^{2}+\sum_{l(i, j) \oplus} P_{l(i, j)}^{L}=0, & j=1,2, . ., n \\
0 \leq P_{j}^{H} \leq \bar{P}_{j}^{H}, & j=1,2, \ldots, n ; \\
0 \leq P_{j}^{2} \leq \bar{P}_{j}^{2} & j=1,2, \ldots, n ; \\
\underline{P}_{l(i, j)}^{L} \leq P_{l(i, j)}^{L} \leq \bar{P}_{l(i, j)}^{L}, & l(i, j)=1,2, \ldots, m,
\end{array}
$$

where $P_{j}^{H}, \bar{P}_{j}^{H}, P_{j}^{2}, \bar{P}_{j}^{2}$-correspondingly covered demand and load demand capacity, used and available generating capacities of $\mathrm{j} \mathrm{TZ} ; P_{l(i, j)}^{L}, \bar{P}_{l(i, j)}^{L}, \underline{P}_{l(i, j)}^{L}{ }^{-}$ communication power flow and its limiting values in the forward (from the $\mathrm{i}$-th $\mathrm{TZ}$ to the $\mathrm{j}$-th) and reverse directions; $c_{j}^{H}$-the coefficients reflecting the cost indicators of the restriction of consumers of the $\mathrm{j}$-th $\mathrm{TZ}$ are taken equal to unity; $V$-many $\mathrm{TZ}$ pairs with interconnected system-forming; $n(m)$ - the number of $\mathrm{TZ}$ (backbone links) EPS.

To take into account the cross sections, correction of constraints (5) is necessary by changing the power MPF levels for the bonds included in a given cross section to infinitely large values. In addition, it is necessary to introduce additional restrictions on controlled sections in the form of:

$$
\underline{P}_{k} \leq \sum_{l \in \mathcal{U}} P_{l}^{L} \leq \bar{P}_{k}, \quad k=1,2, \ldots, K,
$$

where $P_{l}^{L}$-calculated power transfer via $l$-th connection; $\bar{P}_{k}, \underline{P}_{k}$-power flow limit values for the kth section in the forward and reverse directions; $U-$ the set of 1-bonds included in the k-th section; $K$-number of sections considered.

\section{Comparison of balance sheet reliability indicators for schemes of various dimensions}

In 2011-2012. On the instructions of JSC SO UES, STC UES OJSC, a model of the design scheme of the UES of Russia was developed, which includes 56 territorial zones and 102 system-forming links between them (Fig. 3). For this scheme, MPF capacities between the allocated territorial zones were obtained. The source of information was the materials of the report on work of the S\&D Russia UES for 2012-2019. 


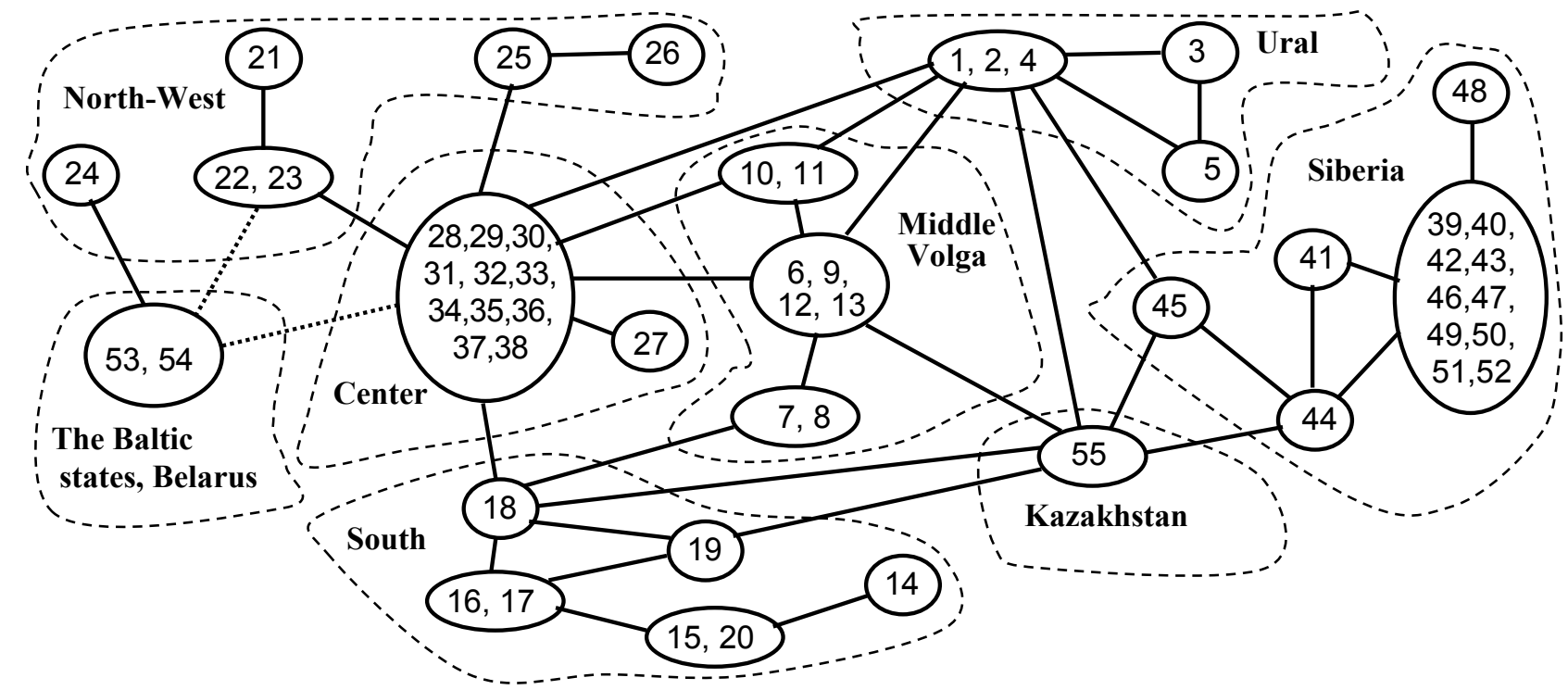

Fig. 4. The UES model of Russia, presented form zones of free power flow (ZFPF).

It is quite obvious that for a really existing composition of generating equipment, their accident rate, and the predicted maximum load values, such sufficiently large design schemes are of certain interest from the standpoint of identifying critical reliability zones and "weak" connections between them. The justification of the means of ensuring balance reliability operational power reserves for such schemes is fraught with significant difficulties, both of a computational nature and, to a greater extent, of information.

Based on the model of the design scheme of the UES of Russia, presented in Fig. 3, two more were developed. One was prepared in accordance with the recommendations of the MR [4] (in Fig. 3 the numbers of TZ included in the UES are shown in the caption), the other, in accordance with the regulatory document ${ }^{\mathrm{e}}$ for solving the CPT problem in the UES of Russia (Fig. 4).

In the table 1 presents the results distribution operational capacity reserve UES, which are purely research-based. Information stuffing on the composition of the generating equipment, its accident rates, the MPF levels of the power of the backbone links were presented by SO UES JSC. The levels of energy consumption of $\mathrm{TZ}$ are taken from the work of the S\&D Russia UES. Forms of changes in the daily load schedule and forecasting errors are presented by SO UES. Important is the constancy of information for all the presented calculations with different representations of the model of the calculation scheme of the UES of Russia. The results speak for themselves - the differences in the TZ reservation levels are very slight. The decrease in the operational power reserve with a decrease in the number of considered territorial zones from 56 to 9 amounted to only $300 \mathrm{MW}$, or $0.19 \%$ with respect to the irregular maximum load (Table 3). The explanation for this is quite simple - inside the UES (Fig. 3), the MPF levels of the communication power practically do not limit the transfer of power from one node to another. The very same situation is observed when instead of MPF is taken into account by the constraints of the flow restriction over the controlled sections. We should not have expected another, due to the lack of information and the conditional formation of MPF over controlled sections on the basis of data on MPF link.

Table 1 - the Distribution operational reserve for UES with a different presentation scheme UES of Russia (the work of the S\&D UES of Russia for 2014)

\begin{tabular}{|c|c|c|c|c|}
\hline & \multirow[b]{2}{*}{ 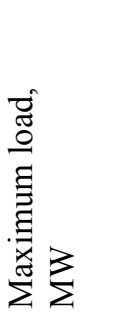 } & \multicolumn{3}{|c|}{ Operational reserve, $\mathrm{MW} / \%$} \\
\hline & & 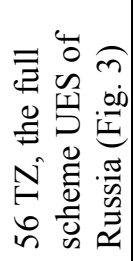 & 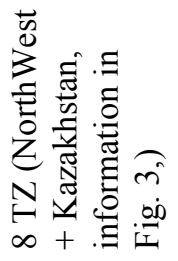 & 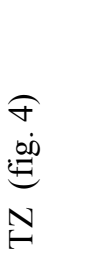 \\
\hline $\begin{array}{c}\text { UES of } \\
\text { Russia } \\
\text { without } \\
\text { East }\end{array}$ & 157670 & $\begin{array}{c}14101 / \\
8.943\end{array}$ & $\begin{array}{l}13801 / \\
8.753\end{array}$ & $\begin{array}{c}14076 / \\
8.928\end{array}$ \\
\hline Ural & 37349 & $\begin{array}{c}1703 / \\
4.56\end{array}$ & $\begin{array}{c}1953 / \\
5.23\end{array}$ & $\begin{array}{c}1703 / \\
4.56\end{array}$ \\
\hline $\begin{array}{l}\text { Middle } \\
\text { Volga }\end{array}$ & 18088 & $\begin{array}{c}343 / \\
1.9\end{array}$ & $\begin{array}{l}293 / \\
1.62\end{array}$ & $\begin{array}{l}293 / \\
1.62\end{array}$ \\
\hline South & 15357 & $\begin{array}{l}637 / \\
4.15\end{array}$ & $\begin{array}{l}587 / \\
3.82\end{array}$ & $\begin{array}{l}612 / \\
3.99 \\
\end{array}$ \\
\hline $\begin{array}{l}\text { North- } \\
\text { west }\end{array}$ & 15731 & $\begin{array}{l}2044 / \\
12.99\end{array}$ & $\begin{array}{l}1944 / \\
12.36\end{array}$ & $\begin{array}{l}2094 / \\
12.99\end{array}$ \\
\hline Center & 38556 & $\begin{array}{l}6158 / \\
15.97\end{array}$ & $\begin{array}{l}6108 / \\
15.84\end{array}$ & $\begin{array}{l}6158 / \\
15.97\end{array}$ \\
\hline Siberia & 32589 & $\begin{array}{c}3216 / \\
9.87\end{array}$ & $\begin{array}{c}2916 / \\
8.95\end{array}$ & $\begin{array}{c}3216 / \\
9.87\end{array}$ \\
\hline
\end{tabular}

${ }^{\mathrm{e}}$ Order of the Ministry of Energy of Russia dated 04/06/2009, No. 99 (as amended on 12/28/2016) "On approval procedure for determining zones free flow of electric energy (power)" (Registered in the Ministry Justice of Russia on June 29, 2009 No. 14153). 


\section{Conclusion}

Justification of the operational component of the normative reserve of power to ensure balance reliability in the conditions of the power market and its commercial selection in modern conditions allows the use of the model of the design scheme of the UES of Russia in the form of integrated power systems with the possible fragmentation of some of them into two or three. This greatly simplifies the process of obtaining initial information from the work "Scheme and development programs of the UES of Russia for a seven-year period" and the computational process with acceptable errors in obtaining the result.

\section{References}

1. Chukreev Yu.Ya. Models ensuring reliability of electric power systems. Syktyvkar: Komi Scientific Center, Ural Branch of the Russian Academy of Sciences, $1995.176 \mathrm{p}$.

2. Chukreev Yu.Ya., Chukreev M.Yu. Models assessing balance sheet reliability indicators for managing development of electric power systems. Syktyvkar: Komi Scientific Center, Ural Branch of the Russian Academy of Sciences, 2014, 207 p.

3. Kovalev G.F., Lebedeva L.M. Reliability of power systems. Novosibirsk: Nauka, 2015, 224 p.

4. Guidelines for designing development of energy systems. (Approved by Order of the Ministry of Energy of Russia dated June 30, 2003, No. 281). M $\therefore$ Ministry of Energy of the Russian Federation, CO 153-34.20.118-2003. 